\title{
The Design and the Properties of a Jet Engine with the Rear Bypass of the Air
}

\author{
Milan Balara ${ }^{1}$, Alexander Balara ${ }^{1}$, Darina Matisková ${ }^{1}$ \\ ${ }^{1}$ Technical University of Kosice, Faculty of Manufacturing Technologies with a seat in Presov \\ Bayerova 1, 08001 Presov, Slovak Republic
}

\begin{abstract}
The article describes the original design of the reaction turbofan engine with rear bypass of the air induced by aerodynamic bypass duct. The article also presents the description of a new proposed design, including the principle and a detailed description of the bypass equipment documented by measurements, graphs and mathematical outputs.
\end{abstract}

Keywords: turbofan engine, bypass equipment, aerodynamics, aerodynamics paradox, fuel, diffuser,

\section{Introduction}

The article describes the design of the turbofan engine with rear bypass of the air induced by the aerodynamic bypass duct. The design is based on the principle of gas flow in the Venturi tube referred to as the aerodynamics paradox. The motion of the bypassing air is a result of the effects of the pressure drop between the flow of the bypassing air and the flow of combustion gases. The article presents the principle and description of the bypass equipment as well as the results of measurements of functional models.

DOI: 10.18421/TEM94-62

https://doi.org/10.18421/TEM94-62

Corresponding author: Darina Matisková, Technical University of Kosice, Faculty of Manufacturing Technologies with a seat in Presov, Department of Industrial Engineering and Informatics, Bayerova 1, 08001 Presov, Slovak Republic.

Email: darina.matiskova@gmail.com,

Received: 28 July 2020.

Revised: 03 November 2020.

Accepted: 16 November 2020.

Published: 27 November 2020.

(cc) BY-NC-ND (C) 2020 Milan Balara, Alexander Balara \& Darina Matisková; published by UIKTEN. This work is licensed under the Creative Commons AttributionNonCommercial-NoDerivs 4.0 License.

The article is published with Open Access at www.temjournal.com
The testing of functional models and the measurements were carried out using the electric jet engine in the version of a single-flow engine and a turbofan engine. The results are presented in tables and graphs contained in the article, and from the technical point of view they are rather encouraging. The proposed design represents the subject of the registered Utility Model No. 8725 in the Slovak Republic and of the registered Utility Model No. 33657 in the Czech Republic.

\section{Original Design}

Reaction engines include rocket engines and jet engines. Rocket engines are reaction engines that operate independently from the environment. They draw fuel and an oxidising medium from a tank; they may therefore be also operated in vacuum (cosmic space). They are based on the action-reaction principle. Fuel combustion produces combustion gases which are, at high velocities, released from the exhaust nozzle of the engine. Their reactive effects exert a force in the direction opposite to the engine and thus also to the means of transport comprising the engine [5],[6],[7]. The effects of the expelled combustion gases (the rocket engine thrust) are proportional to the product of the mass of combustion gases and their expulsion velocity. Depending on the fuel state, rocket engines are divided into engines with liquid fuel and engines with solid fuel.

A rocket engine holds a special position among combustion engines:

- During the operation, it does not draw the working medium from the atmosphere; it must contain a sufficient reserve not only of the fuel, but also of an oxidising agent.

- The usable output of the engine is not mechanical work, but the reaction effects of combustion gases.

- The primary energy transformation system of the engine does not contain movable parts, except for auxiliary systems (e.g. pumps and nozzle turning). 
The second group of reaction engines consists of jet engines. In the past, the key representative of this type of engines was a jet engine, now it is a turbofan engine. The turbofan engine (also referred to as a fanjet) is an aircraft engine operating on the basis of the action-reaction principle. When compared to the jet engine, it also contains a fan and a low-pressure compressor driven by another turbine. The air entering the engine is first compressed by the fan. A certain portion of the air (determined by the bypass ratio) flows into the high-pressure part of the engine, and the rest bypasses it through the bypass duct. The thrust of the engine is induced by the effects of both those gas flows. [15]

At the inlet, there are high-pressure and lowpressure compressors with separate coaxial rotors which compress the air and thus increase its temperature to the value required for the most efficient ignition. The air therefore flows into a diffuser which slows down the air while maintaining its temperature. Next, there are combustion chambers where the fuel is added. This is followed by the ignition which causes a huge increase in the volume of gases. Combustion gases pass through the turbines of the high-pressure compressor and the turbine fan to which they render most of their energy. Then they exit the high-pressure part of the engine and are mixed with the bypassing air. A major portion of the engine thrust with a high bypass ratio originates in the bypass duct and is induced by the fan. The amount of the air flowing through the turbofan engine is significantly higher than through the jet engine. The velocity of inlet gases is therefore lower at the same engine output. The amount of the air flowing through the turbofan engine is significantly higher than through the jet engine because at a lower velocity it is possible to achieve at the outlet a better ratio of momentum to energy which determines the consumption of energy required to induce the unit thrust. The maximum percentage of saved fuel or energy in the turbofan engine, when compared to the jet engine, amounts to $28.57-33 \%$ at most. This is one of the reasons why nowadays almost all civil and military airplanes are equipped with this type of engines.[1] Turbofan engines in military airplanes usually exhibit a low bypass ratio and comprise additional combustion.

Turbofan engines are most efficient at velocities ranging from 500 to $1,000 \mathrm{~km} /$ hour, i.e. velocities at which most commercial airplanes are operated. Turbofan engines maintain their efficiency level above that of ordinary jet engines at low supersonic velocities (up to approximately Mach 1.6), but they may also be efficient with a continuous use of additional combustion at the velocity of Mach 3 and higher. These reaction turbofan engines certainly offer many advantages and have therefore been increasingly used. Their disadvantage, however, is that they need fans of relatively large diameters. This imposes higher requirements for manufacturing, used materials and levelling. Fan diameters are much larger than turbines and combustion chambers. Together with a necessity of the bypass duct, it is also necessary to substantially increase the engine diameter, and this imposes even more complex requirements for designs of other airplane parts (e.g. a landing gear). When compared to the original jet engine design, turbofan engines comprise a higher amount of movable parts, and this affects their manufacture cost, failure rate and service life.

\section{Proposed Design of the Turbofan Engine with the Rear Bypass of the Air}

The drawbacks listed above are eliminated by the design in which there is a throttling nozzle at the end of the tube for the expulsion of combustion gases. The nozzle is located inside the bypass duct which ends with a nozzle through which the mixture of combustion gases from the throttling nozzle and the air coming from the front apertures of the bypass duct passes (see Fig. 2 and 3). This part of the jet engine is referred to, from the theoretical point of view, as an ejector.[1],[2] In this particular case, it represents a simplified modification of the gas ejector applied to the exit part of the jet engine. As a result of the Bernoulli's principle (the aerodynamics paradox - reduced pressure of the propelling medium after reducing the pipe diameter), the particles of the bypassing air are carried away in the direction of the combustion gases flowing from the throttling nozzle of the jet engine.[3],[5] The mass of the gases exiting the reaction turbofan engine with the rear bypass of the air consists of the mixture comprising combustion gases of the reaction engine and the bypass air. The bypassing air is drawn into the bypass duct through its front part into which the rear part of the reaction engine is inserted together with the throttling nozzle.

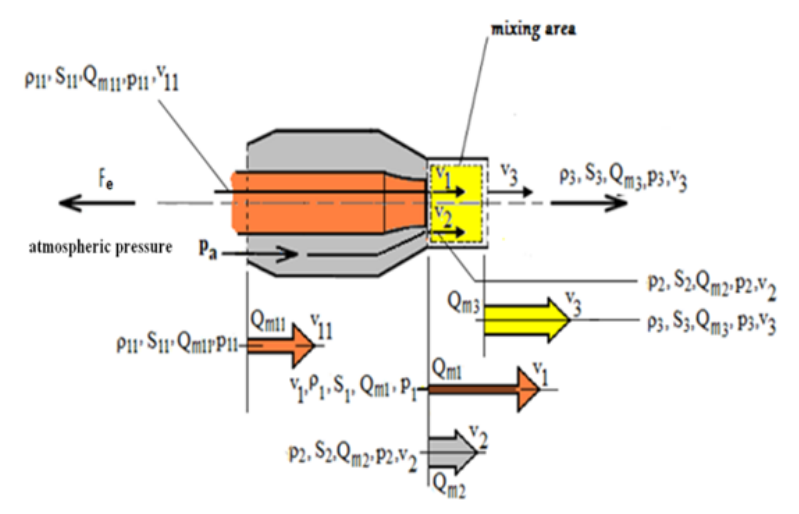

Figure 1. Schematic of the ejector with a throat and indicated parameters used in the basic calculation 
formulas: 1 -driving flow, 2 -driven flow, 3 - outlet from the throat.

Following correlations apply to individual parameters shown in Fig. 1:

Correlations between pressures:

$$
\mathrm{p}_{2}=\mathrm{p}_{\mathrm{a}} ; \quad \mathrm{p}_{3}>\mathrm{p}_{2}>\mathrm{p}_{1} ; \quad \mathrm{p}_{11}>\mathrm{p}_{1} ; \quad \mathrm{p}_{1}<\mathrm{p}_{3}
$$

Correlations between velocities:

$$
\mathrm{v}_{1}>\mathrm{v}_{3}>\mathrm{v}_{2}
$$

Correlations between mass flow rates:

$\mathrm{Q}_{\mathrm{m} 1}+\mathrm{Q}_{\mathrm{m} 2}=\mathrm{Q}_{\mathrm{m} 3}$

Pressure gradient between nozzles $\mathrm{d}_{\mathrm{pe}}$ :

$\mathrm{d}_{\mathrm{pe}}=\mathrm{p}_{2}-\mathrm{p}_{1}$

The used parameters have the following meanings:

$\mathrm{D}_{3}$ throat diameter[m]

$\mathrm{Q}_{\mathrm{m} 11}$ input medium flow rate

$\mathrm{Q}_{\mathrm{m} 3}$ output medium flow rate

$\mathrm{v}, v$ velocity $\quad\left[\mathrm{m} . \mathrm{s}^{-1}\right]$

$\rho$ medium density $\left[\mathrm{kg} . \mathrm{m}^{-3}\right]$

Scross-sectional area $\left[\mathrm{m}^{2}\right]$

$\mathrm{D}$ diameter [m]

$\mathrm{Q}$ driving medium flow rate $\left[\mathrm{m}^{3} . \mathrm{s}^{-1}\right]$

$\mathrm{p}$ pressure $[\mathrm{Pa}]$

$\mathrm{P}$ power [W]

$\mathrm{Q}_{\mathrm{m}}$ medium mass flow rate $\left[\mathrm{kg} . \mathrm{s}^{-1}\right]$

$F_{p}$ force exerted on the ejector[N]

$\mathrm{F}_{\mathrm{e}}$ force exerted on the engine [N]

The parameters contained in the descriptions above and below and in calculations are indexed as follows: 1 - parameters of the propelling environment; 11 - parameters of the propelling environment passing index 1;

2 - parameters of the propelled (bypass)

environment;

3 - parameters at the outlet from the

equipment (from the throat or nozzle of the bypass duct).

In the bypass duct, the particles of combustion gases mix with the particles of the bypass air of the bypass duct. Hence, these air particles are carried away by the particles of combustion gases and, as a result, they move faster. A significant portion of the previously unused kinetic energy of combustion gases is transferred to the bypass air in the bypass duct. As a result, a larger amount of gases is expelled from the system (despite a lower velocity), and hence the thrust of the engine is higher.[5]

\section{Description of the Proposed Design}

Fig. 2 and 3 represent exemplary embodiments of the present equipment, including the overall arrangement of individual functional parts. The reaction turbofan engine with the rear bypass of the air consists of the reaction engine 1 with the bypass duct 2 attached to the reaction engine 1 using the anchors 4 of the bypass duct 2 . The flow of combustion gases 5 of the reaction engine 1 coming from the nozzle 3 of the reaction engine 1 consists of the mixture 6 of combustion gases 5 of the reaction engine 1 and the bypass air 7 . The bypass air 7 is drawn into the bypass duct 2 through its front part into which the rear part of the reaction engine 1 is inserted together with the nozzle 3 . The bypass duct 2 is attached to the reaction engine 1 (e.g. using the anchors 4 of the bypass duct 2). Together they form a firmly connected unit. The bypass air 7 is drawn into the bypass duct through an annulus-shaped aperture wherein its outer diameter is determined by the diameter of the front part of the bypass duct 2 .

The inner diameter of the annulus is determined by the diameter of the reaction engine1. The shapes of the central and rear parts of the bypass duct 2 are

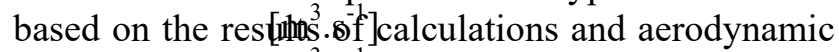
tests so that [tme.s flow of the bypass air 7 and combustion gases 5 of the reaction engine 1 provided the maximum efficiency of the designed unit which therefore consists of the reaction turbofan engine with the rear bypass of the air. Its advantages are almost identical to those of the reaction turbofan engine with the front air bypass.[5]

In such engine, the flow of the bypass air 7 is induced by the impact of the air as the reaction engine moves forward. Also, in the inner space of the bypass duct 2 air 7 moves (in compliance with the Bernoulli's principle) in the bypass duct 2 towards the rear constricted part. Such movement is caused by the difference in air pressures in the front and rear parts of the bypass duct 2 . In the bypass duct 2 , the particles of combustion gases $5 \mathrm{mix}$ with the particles of the bypass air 7 of the bypass duct 2 . These air particles are therefore carried away by the particles of combustion gases and their movements become faster. A substantial portion of the previously unused kinetic energy of combustion gases 5 is transferred to the bypass air 7 in the bypass duct 2 .

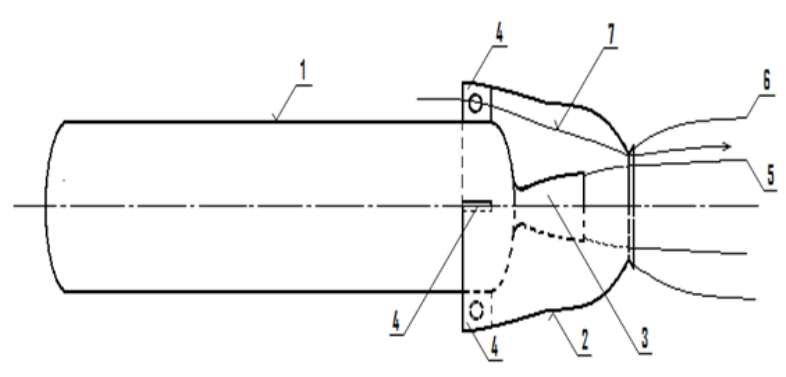

Figure 2. Reaction engine with the rear bypass of the air. 1 reaction engine, 2 bypass duct, 3 (throttling) nozzle, 4 anchor of the bypass duct, 5 flow of combustion gases, 6 mixture of combustion gases and the bypass air, 7 bypass air. 


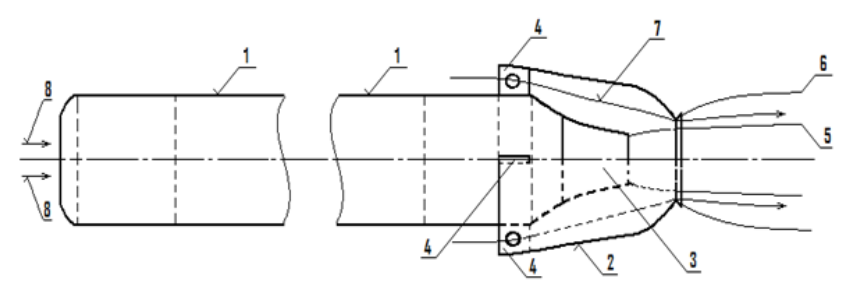

Figure 3. Jet engine with the rear bypass of the air. 1 jet engine, 2 bypass duct, 3 throttling nozzle, 4 anchor of the bypass duct, 5 flow of combustion gases, 6 mixture of combustion gases and the bypass air, 7 bypass air.

At a selected thrust value, the amount of energy saved as a result of replacing the jet engine with its turbofan equivalent ranged from $31.8 \%$ to $33 \%$ [4] [5]. These data resulted from the comparison of the specific consumption data. When compared to the turbofan engine with the bypass ratio 8 , this range was $28.57 \%$ to $33.00 \%$ at most [5]. When the bypass ratio of the turbofan engine is 24 , this value will be $35.7 \%$. In this case, the value is merely theoretical as it is not actually possible to construct such engine [4],[5]

\section{Measured Functional Model, its Modifications and Measurement Results}

For the sake of maximum possible structural simplicity and maximum functional efficiency, the final design of the bypass equipment was created applying the concept depicted in Fig. 4. This particular design does not comprise the ejector throat as the space where the gases are mixed. Instead, such mixing runs in the space before the nozzle of the bypass duct (yellow area) which begins in the plane of the throttling nozzle.

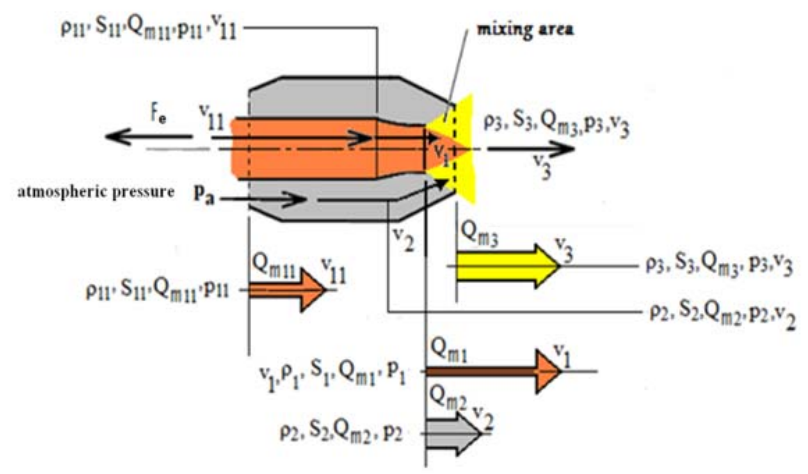

Figure 4. Schematic of the bypass equipment (modified ejector) with indicated parameters used in the basic calculation formulas: 1 and 11-driving flow, 2 -driven flow, 3 -driven flow behind the plane of the nozzle of the bypass duct.

This version of the gas ejector possesses the following characteristic features:
- Only the minimum amount of functional parts has been used. The designed ejector does not comprise an air intake, throat or a diffuser;[3],[5]

- The throttling nozzle plane (index 1) has been moved relative to the plane of the nozzle of the bypass duct (index 3). This distance may be calculated or identified empirically, or both methods may be applied;

- The properties of the designed ejector are determined primarily by the following parameters: diameter and area of the throttling nozzle $\mathrm{D}_{1}, \mathrm{~S}_{1}$; diameter and area of the nozzle of the bypass duct $\mathrm{D}_{3}, \mathrm{~S}_{3}$; and the distance between them $1_{13}$.

Individual parameters depicted in Fig. 4 are subject to the correlations specified for the parameters shown in Fig. 1. The tensile force exerted on the bypass duct body may be calculated using the formula of the law of conservation of momentum at zero loss:

$F_{p}=F_{e}=v_{1} Q_{m 1}+p_{1} S_{1}+v_{2} Q_{m 2}+p_{2} S_{2}-v_{3} Q_{m 3}-p_{3} S_{3}(\mathrm{~N})$

\section{[4.1]}

The principle and function of the newly designed jet engine was verified using an electric turbofan engine with the rated input power of $350 \mathrm{~W}$, QXmotor make, QF2611-4500KV type, which is intended for propelling microjets and drones. The 5blade propeller with the diameter of $65 \mathrm{~mm}$ was driven by a three-phase electric motor with a converter, a controlling element and batteries Li-Pol $12 \mathrm{~V}, 25 \mathrm{~A}$. The fan body was attached to the outlet tube to which the throttling nozzle was attached at the opposite end. Such assembly was inserted into the bypass duct and secured against displacement using screws (anchors). This engine is depicted in Fig. 3, and Fig. 5 through 8. Its diameter was 130 $\mathrm{mm}$, the total length was $220 \mathrm{~mm}$ and the weight was $0.90 \mathrm{~kg}$. The throttling nozzle diameter $\mathrm{D}_{1}$ was $5 \mathrm{~cm}$, the diameter of the nozzle of the bypass duct $\mathrm{D}_{2}$ was $7 \mathrm{~cm}$ and the distance between the nozzles $1_{13}$ was 2 cm. [8],[9].

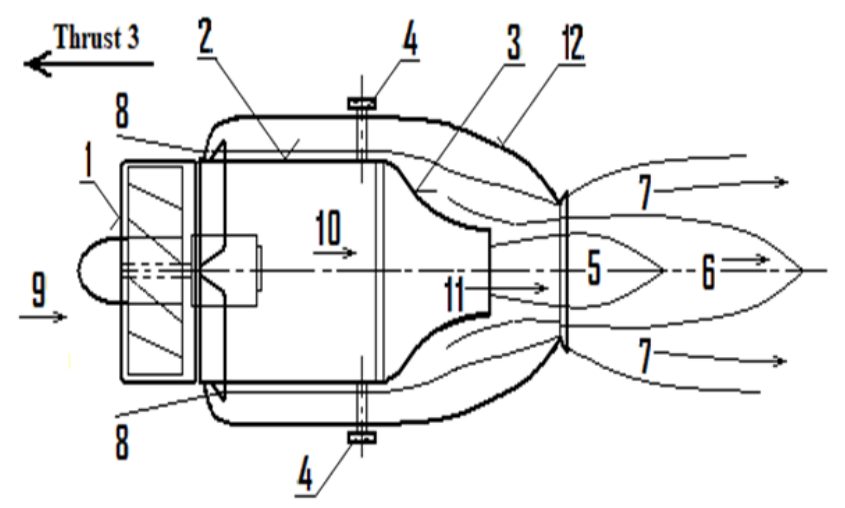

Figure 5. Jet engine with the rear bypass of the air. Functional model. 1 reaction engine, 2 outlet tube, 3 nozzle, 4 anchor of the bypass duct, 12 bypass duct, 5 flow of combustion gases, 6 concentrated mixture of combustion gases and the bypass air, 7 mixture of combustion gases and the bypass air. Thrust 3 is the thrust of the turbofan engine with a throttling nozzle. 


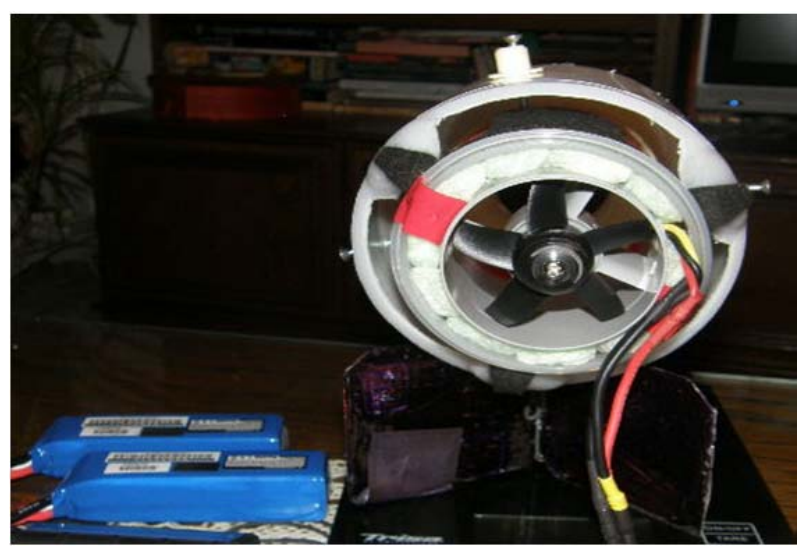

Figure 6. Jet engine with the rear bypass of the air and power supply batteries. A front view.

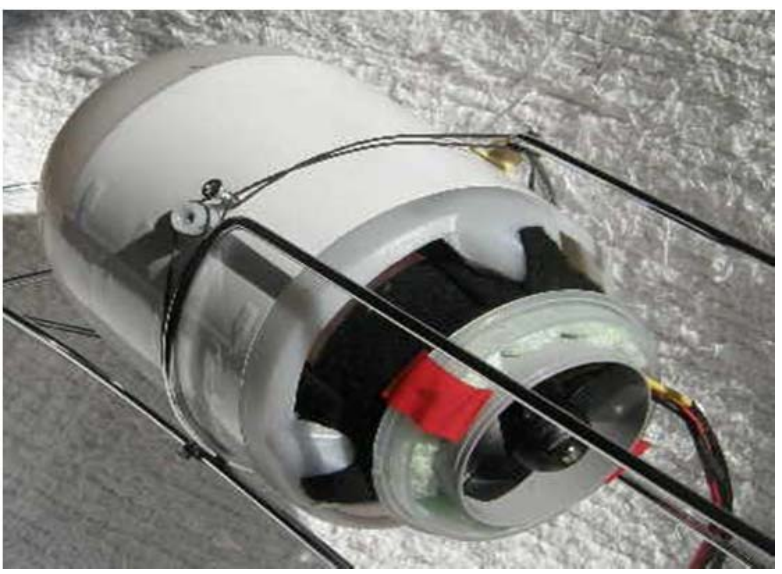

Figure 7. Jet engine with the rear bypass of the air

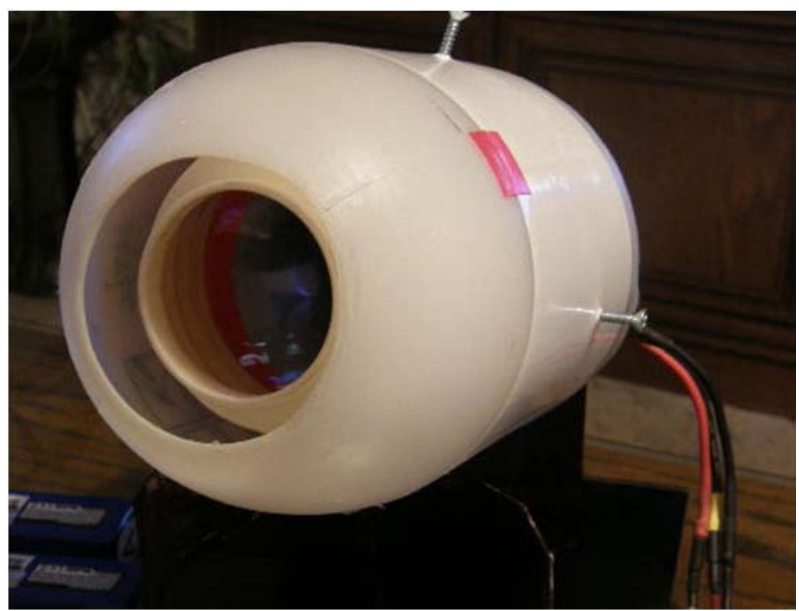

Figure 8. Jet engine with the rear bypass of the air. The rear part.

The measurements carried out using the depicted jet engine were primarily aimed at identifying the correlation between the engine thrust $\mathrm{F}_{\mathrm{e}}$ and the input power P. Also, the current I of the engine was measured at each value of the input power, as well as the value of voltage $U$ at engine terminals. Table 1 contains the values of engine thrust depending on the input power at individual configurations of the measured engine [9],[10].
Measurements results are contained in Tables 1-3, and they were recorded in a form of graphical characteristics. The main characteristics represent the correlation between the engine thrusts $F_{e}$ and the input power $\mathrm{P}$, i.e. $\mathrm{F}_{\mathrm{e}(\mathrm{P})}=\mathrm{f}(\mathrm{P})$, (designated as Thrusts 1 through 4). The characteristics represent the percentages of the differences between two parameters of Thrust 1 through $\mathbf{4}$ relative to relevant values of Thrust 1. They are designated as Delta 0 through 2. The values of these characteristics were calculated as follows:

Delta $1=$ (Thrust 3 - Thrust 2).100/Thrust 1

Delta 2 = (Thrust 2 - Thrust 1).100/Thrust 1(\%) (4.2)

Delta $0=$ Delta $1+$ Delta 2

Table 1. Delta parameters in graphs and tables represent the percentage of an increase in the engine thrust

\begin{tabular}{|c|c|c|c|c|c|c|c|}
\hline $\begin{array}{c}\text { Power in P } \\
(\mathrm{W})\end{array}$ & 50 & 100 & 150 & 200 & 250 & 300 & 350 \\
\hline $\begin{array}{c}\text { Thrust 1 } \mathrm{F}_{1} \\
(\mathrm{~g})\end{array}$ & 50 & 112 & 165 & 200 & 230 & 253 & 275 \\
\hline $\begin{array}{c}\text { Thrust 2 } \mathrm{F}_{2} \\
(\mathrm{~g})\end{array}$ & 80 & 140 & 193 & 245 & 293 & 328 & 350 \\
\hline $\begin{array}{c}\text { Thrust 3 } \mathrm{F}_{3} \\
(\mathrm{~g})\end{array}$ & 89 & 164 & 234 & 300 & 346 & 380 & 400 \\
\hline $\begin{array}{c}\text { Delta } 0 \mathrm{~d}_{0} \\
(\%)\end{array}$ & 78 & 46.43 & 47.88 & 50 & 47.4 & 47.82 & 45.48 \\
\hline $\begin{array}{c}\text { Delta } 1 \\
\text { d1(\%) }\end{array}$ & 18 & 21.43 & 24.85 & 27.5 & 23.04 & 20.55 & 18.18 \\
\hline $\begin{array}{c}\text { Delta 2 } \\
\mathrm{d}_{2}(\%)\end{array}$ & 60 & 25 & 23.03 & 22.5 & 27.39 & 29.64 & 27.3 \\
\hline
\end{tabular}

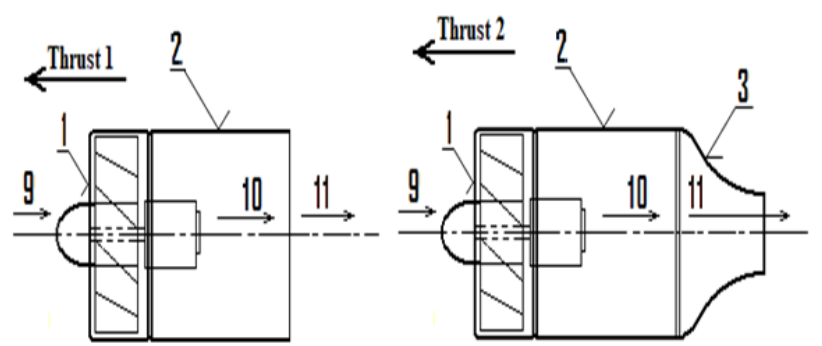

Figure 9. Single-jet electric jet engines. Left: Single-jet fan engine: 1 electric fan, 2 outlet tube, 9 intake air, 10 outlet air of the engine, 11 outlet air, Thrust 1 is the thrust of the single-jet fan engine Right: Single-jet fan engine with a throttling nozzle: 1 electric fan, 2 outlet tube, 3 throttling nozzle, 9 inlet air, 10 outlet air of the engine, 11 outlet air from the throttling nozzle, Thrust 2 is the thrust of the single-jet fan engine with a throttling nozzle.

According to data in Table 1., Fig. 10. shows all the measured characteristics for individual configurations of jet engines depicted in Fig. 5 and 7. Delta parameters in graphs and tables represent the percentage of an increase in the engine thrust for individual configurations relative to the basic configuration (Thrust 1). 


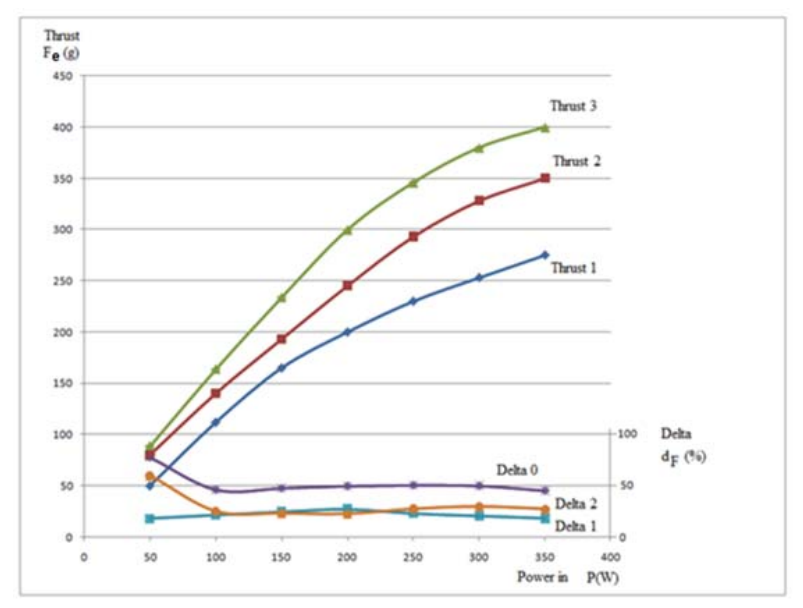

Figure 10. Jet engine with the rear bypass of the air. The curve of the correlation between $F_{e}$ and input power $F_{e}=$ $f(P)$, the curve of Thrust 1-3 values (in grams). In the lower part, there is the curve of the correlation between an increase in the Delta 0-2 (in \%) and the input power $d_{F}=$ $f(P)$, the curve of Delta $0-2$. The values of graph parameters are contained in Table 1.

Table 2. Measured values

\begin{tabular}{|c|c|c|c|c|c|c|c|}
\hline $\begin{array}{c}\text { Power in } \\
\mathrm{P}(\mathrm{W})\end{array}$ & 50 & 100 & 150 & 200 & 250 & 300 & 350 \\
\hline $\begin{array}{c}\text { Delta 0 } \\
(\%)\end{array}$ & 78 & 46.43 & 47.88 & 50 & 50.79 & 50.19 & 45.48 \\
\hline $\begin{array}{c}\text { Delta 1 } \\
(\%)\end{array}$ & 18 & 21.43 & 24.85 & 27.5 & 23.04 & 20.55 & 18.18 \\
\hline $\begin{array}{c}\text { Delta } 2 \mathrm{~d}_{2} \\
(\%)\end{array}$ & 60 & 25 & 23.03 & 22.5 & 27.39 & 29.64 & 27.3 \\
\hline
\end{tabular}

Table 2. contains the measured values for graphs shown in Fig. 11.

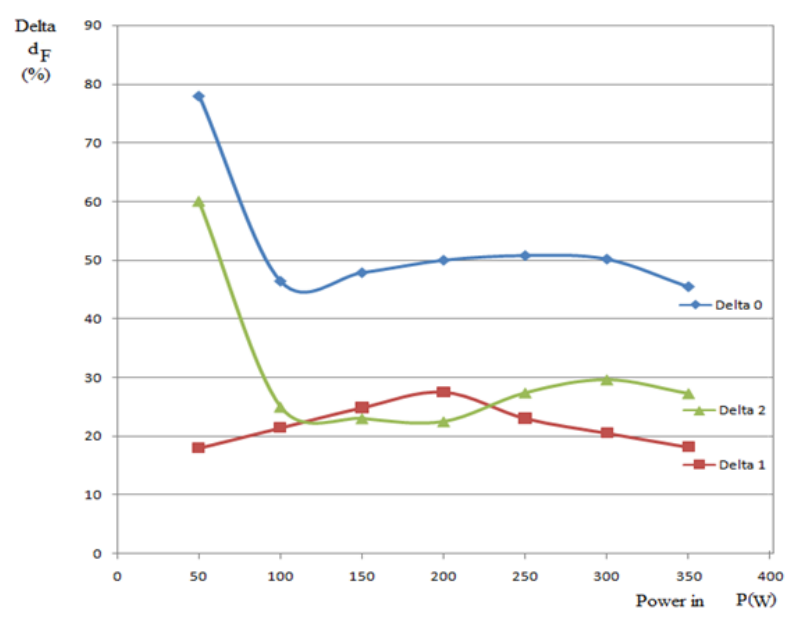

Figure 11. The curve of the correlation between an increase in the thrust Delta 0-2 (in \%) and the input power $d_{F}=f(P)$, the curve of Delta 0-2. The values of the graph parameters are listed in Tables 1. and 2.

Fig. 12. shows the characteristics of the thrust of engines $F_{e}$ depending on the input power $F_{e}=f(P)$, the curves of Thrusts 1 and $3,\left(\mathrm{~F}_{\mathrm{e} 1} \operatorname{andF}_{\mathrm{e} 3}\right)$. For Thrust
3 , the curve represents the correlation with an increase in the thrust Delta 0 , i.e. $d_{F}=f(P)$.

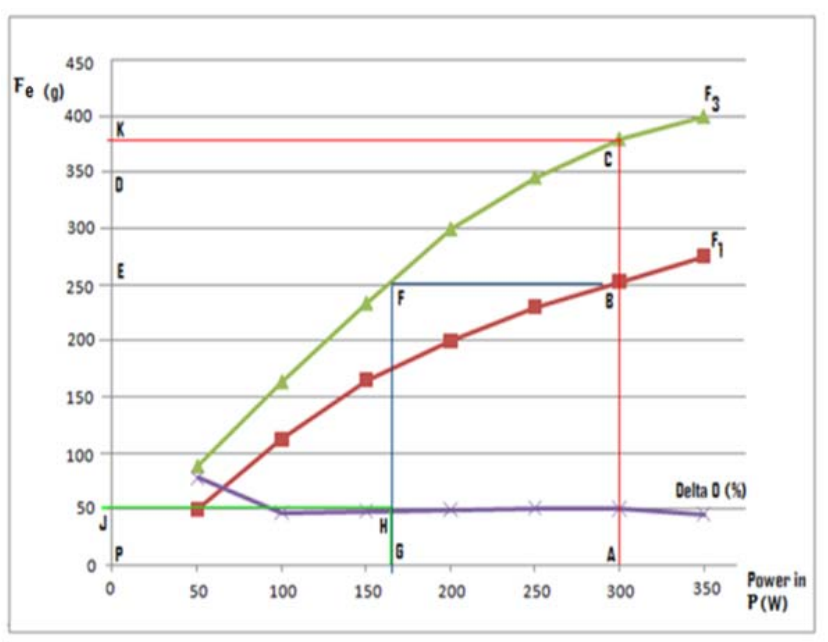

Figure 12. The $F_{3}$ characteristics is the curve of the thrust depending on the input power for the jet engine with the

rear bypass of the air; F1 is the curve of the thrust depending on the input power for the jet engine. Delta 0 is the curve of an increase in the thrust of engine $F_{e}$ (in \%) depending on the input power following the application of the equipment for the rear bypass of the air

The above described comparison of these characteristics may be used for the quantitative evaluation of an increase in the thrust and the saved input power achieved with the examined engine following the application of the equipment for the rear bypass of the air.[14] This is documented in the relevant Figure with the data on the engine working in the operating point B. In this point, the input power for engines $\mathrm{F}_{\mathrm{e} 1}$ and $\mathrm{F}_{\mathrm{e} 3}$ amounted to $300 \mathrm{~W}$. Engine $\mathrm{F}_{\mathrm{e} 1}$ exhibited the thrust of $250 \mathrm{~g}$ and engine $\mathrm{F}_{\mathrm{e} 3}$ exhibited the thrust of $379 \mathrm{~g}$; the $\mathrm{F}_{\mathrm{e} 3}$ thrust represented a 1.516-fold change of the thrust $\mathrm{F}_{\mathrm{e} 1}$, i.e. $51.6 \%$. This value may also be deducted from the curve of Delta 0. A similar method may be used to set the change of energy consumption in order to achieve the same value of the engine thrust. Energy consumption in the operating point $\mathrm{B}$ for $\mathrm{F}_{\mathrm{e} 1}$ represented $300 \mathrm{~W}$ and the thrust amounted to $250 \mathrm{~g}$. The same value was achieved by the engine $F_{\mathrm{e} 3}$ at the input power of $165 \mathrm{~W}$. The ratio of input powers was $165 \mathrm{~W} / 300 \mathrm{~W}$, i.e. 0.55 . In this case, the saved energy amounted to $135 \mathrm{~W}$, i.e. $45 \%$ [11],[12].

Fig. 13 shows the jet engine with the rear bypass of the air and with a throat behind the nozzle of the bypass duct. The purpose of testing such arrangement was to examine the impact of gases flowing through the throat $\left(l_{\mathrm{k}}=70 \mathrm{~mm}\right)$ on engine thrust values within the entire range of allowed input powers. The measurement results are listed in Table 3. The measured characteristics are shown in Fig. 14 designated as Thrust 4. 


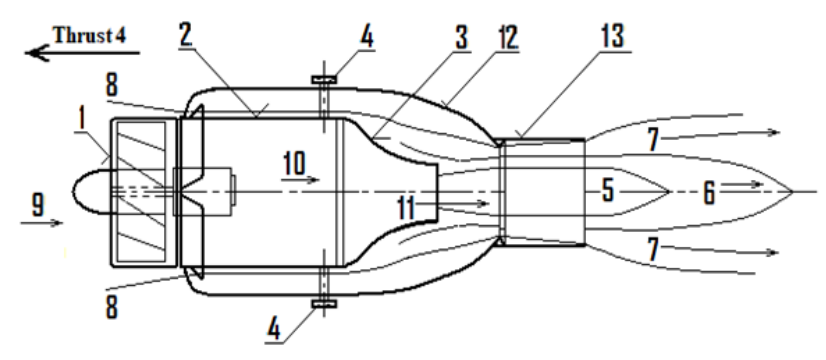

Figure 13. Jet engine with the rear bypass of the air and with a throat. 1 reaction motor, 12 bypass duct, 3 nozzle, 4 anchor of the bypass duct, 5 flow of combustion gases, 6 mixture of combustion gases and the bypass air, 7 bypass air, 13 throat

Table 3. Measurement results.

\begin{tabular}{|c|c|c|c|c|c|c|c|}
\hline Power in $\mathrm{P}(\mathrm{W})$ & 50 & 100 & 150 & 200 & 250 & 300 & 350 \\
\hline Thrust $1 \mathrm{~T}_{1}(\mathrm{~g})$ & 37 & 112 & 165 & 200 & 230 & 253 & 275 \\
\hline Thrust $2 \mathrm{~T}_{2}(\mathrm{~g})$ & 80 & 140 & 193 & 245 & 293 & 328 & 350 \\
\hline Thrust $3 \mathrm{~T}_{3}(\mathrm{~g})$ & 89 & 160 & 234 & 300 & 346 & 374 & 400 \\
\hline Thrust $4 \mathrm{~T}_{4}(\mathrm{~g})$ & 89 & 164 & 220 & 271 & 316 & 350 & 371 \\
\hline
\end{tabular}

The curve of the characteristics clearly indicates that such arrangement has increased the thrust relative to Thrust 2, but relative to Thrust 3 the values were lower in almost the entire curve. An increase in the thrust relative to Thrust 2 was in fact identical in almost the entire curve, except for the area of low input powers (less than $200 \mathrm{~W}$ ) where it gradually decreased.

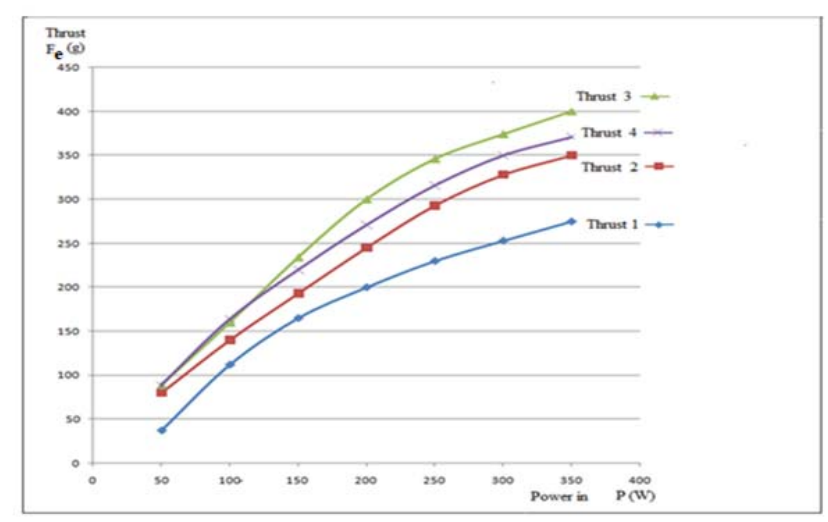

Figure 14. Jet engine with the rear bypass of the air and with the throat (Thrust 4)

\section{Possible Calculations, Basic Calculation Formulas}

Due to the fact that the flow of fluids and gases is a complex process, when designing ejector devices shown in Fig. 1 and 4, it was necessary to adopt a number of simplifying assumptions which facilitated depicting individual flows and solving primarily geometric dimensions of the device [1], [2]. The application of such simplifying assumptions resulted in gross errors thin calculations which needed to be reduced by using various experimentally identified coefficients. The flow in the ejector was simplified into a one-dimensional and a straight-line flow. It was also assumed that the pressure in the mixing chamber $\mathrm{p}_{\mathrm{mc}}=\mathrm{p}_{2}=\mathrm{p}_{\mathrm{a}}$, i.e. the pressure applied to aspirate the air, was constant.[13],[14] The application of such simplifying assumptions resulted in gross errors thin calculations which needed to be reduced by using various experimentally identified coefficients.

The calculation of the bypass equipment, with the abovementioned simplifying assumptions, may be carried out using the following equations:

a) The calculation of the ejector was based on an important assumption of the applicability of the continuity equation, i.e. the law of conservation of mass:

$$
p_{1} \cdot v_{1} \cdot S_{1}+p_{2} \cdot v_{2} \cdot S_{2}=p_{3} \cdot v_{3} \cdot S_{3}\left[\mathrm{~kg} \cdot \mathrm{s}^{-2}\right](5.1)
$$

Therefore, the mass entering the ejector must be equal to the mass expelled from it.

b) The law of conservation of momentum applies and it may be expressed using the forces exerted on the flowing medium (air, gas). A number of simplifying assumptions had to be implemented. We assumed that the values of velocity, pressure and external unit normal vector at cross-sections $\mathrm{S}_{1}, \mathrm{~S}_{2}$ and $\mathrm{S}_{3}$ were constant and that the ejector was in a horizontal position. Gravity $g$ was ignored. We did not consider the signs of flow rate values, i.e. that the inflow was of a positive value and the outflow was of a negative value. We only considered the positive mass flow rate $\mathrm{Q}_{\mathrm{m}}$ and this was then expressed as follows:

$v_{1 x} \cdot Q_{m 1}-p_{1} \cdot n_{1 x} \cdot S_{1}+v_{2 x} \cdot Q_{m 2}-p_{2} \cdot n_{2 x} \cdot S_{2}=v_{3 x} \cdot Q_{m 3}+p_{3} \cdot n_{3 x} S_{3}+F_{p x}$ $[N](5.2)$

Where:

$Q_{m}$ - mass flow rate;

$n$ - normal vector of the passage area;

$F_{p}$ - force exerted on the ejector.

For the given ejector, we considered the component in the direction of the $\mathrm{x}$-axis - the axis of the ejector:

$v_{1 x} \cdot Q_{m 1}-p_{1} \cdot S_{1}+v_{2 x} \cdot Q_{m 2}-p_{2} \cdot n_{2 x} \cdot S_{2}=v_{3 x} Q_{3 m}+p_{3} \cdot n_{3 x} S_{3}+F_{p x}$ $[N](5.3)$

The positive direction of the $\mathrm{x}$-axis was considered in the direction of the flow through the nozzle:

$v_{1} \cdot Q_{m 1}+p_{1} \cdot S_{1}+\left(v_{2} \cdot Q_{m 2}+p_{2} \cdot S_{2}\right) \cos \alpha=v_{3} \cdot Q_{m 3}+p_{3} \cdot S_{3}+F_{p x}$ $[N](5.4)$

where angle $\alpha$ is the angle of the longitudinal axis of the engine relative to the horizontal plane. 
The component of the force exerted on the ejector $F_{p x}$ included the friction loss (provided that the measured pressure values are available) or the calculated loss.

c) The applicability of the law of conservation of energy which may be expressed using the Bernoulli's equations or using the powers:

$$
\left(\frac{v_{1}^{2}}{2}+\frac{p_{1}}{\rho_{1}}\right) \cdot Q_{1} \cdot \rho_{1}+\left(\frac{v_{2}^{2}}{2}+\frac{p_{2}}{\rho_{2}}\right) \cdot Q_{2} \cdot \rho_{2}=\frac{v_{3}^{2}}{2}+\frac{p_{3}}{\rho_{3}}+P_{\text {loss }}
$$

$P_{\text {loss }}-$ power loss

$$
\frac{v_{3}^{2}}{2}+\frac{p_{3}}{\rho_{3}}=\frac{v_{4}^{2}}{\rho_{4}}+Y_{\text {loss }}\left[J . \mathrm{kg}^{1}\right](5.6)
$$

$Y_{\text {loss }}$ - specific energy loss

Bernoulli's equation (5.1) describes fusion of the flow of the driving medium and the flow of the driven medium. It was necessary to consider the simplification mentioned in the introductory section of this chapter. It was assumed that as gases passed through the throat, their velocity and pressure were constant and that the loss only occurred as a result of friction. The following formula, compiled using the powers, probably represents the most complex expression of the development of the medium flow in the throat.[14] This equation was drawn up while considering enthalpy and the temperature. Enthalpy expresses the energy stored in a thermodynamic system and its value therefore depends on state variables of the medium.

$\rho_{1} \cdot v_{1} \cdot S_{1} \cdot\left(\frac{v_{1}^{2}}{2}+h_{1}\right)+\rho_{2} \cdot v_{2} \cdot S_{2} \cdot\left(\frac{v_{2}^{2}}{2}+h_{2}\right)=\rho_{3} \cdot v_{3} \cdot S_{3} \cdot\left(\frac{v_{3}^{2}}{2}+h_{3}\right)+P_{l o s s}$

$[W](5.7)$

Where:

$$
\begin{aligned}
& h \text { - environment enthalpy } \\
& P_{\text {loss }}-\text { power loss }
\end{aligned}
$$

With regard to the energy transfer mechanism (see Chapter 3.1), it was possible to simplify the equation of powers (7) as follows:

$$
P_{1}=P_{2}+P_{\text {loss }}[W]
$$

Subsequently, the simplified energy equation was used to express the efficiency as follows:

$\eta=\frac{P_{2}}{P_{1}} \cdot 100$ where $\eta$ is the efficiency. The formulas above were then used to derive the formula for efficiency $\eta_{p}$ of the ejector based on the powers:

$$
\eta_{p}=\frac{\rho_{2} \cdot Q_{2} \cdot\left[\left(\frac{v_{3}^{2}}{2}+\frac{p_{3}}{\rho_{3}}\right)-\left(\frac{v_{2}^{2}}{2}+\frac{p_{2}}{\rho_{2}}\right)\right]}{\rho_{1} \cdot Q_{1} \cdot\left[\left(\frac{v_{1}^{2}}{2}+\frac{p_{1}}{p_{1}}\right)-\left(\frac{v_{3}^{2}}{2}+\frac{p_{3}}{p_{3}}\right)\right]} \cdot 100
$$

We assumed that the inclination of the ejector axis was constant and the ejector was in a horizontal position, i.e. that there was no gravity g. The calculations in the formula would only differ in a combination of the driving and driven media. The numerator of this formula contains the power acquired by the driven medium as it passed through the ejector, and the denominator contains the power loss of the driving medium. This provided a rather accurate image of the efficiency of the whole ejector [15].

More accurate results may be obtained if we consider the momentum loss and even more losses that occur in nozzle and in the mixing chamber (or in the diffuser). Such losses are determined by the loss coefficients which are defined separately for each part of the ejector (Fig. 1. and 4.) as follows:

$$
\begin{aligned}
& \zeta_{N o z}=\frac{l}{\varphi^{2}}-1 \\
& \zeta_{m c}=\lambda \cdot \frac{l_{m c}}{d_{m c}} \\
& \zeta_{k}=\frac{\lambda \cdot l_{3}}{D_{3}} \\
& \zeta_{D i f}=\left(1-\eta_{D i f}\right) \cdot\left[1-\left(\frac{S_{4}}{S_{3}}\right)^{2}\right]
\end{aligned}
$$

$\lambda$-coefficient of friction (it may be identified using the Moody's Diagram);

$k$ - height of protuberances on the inner surface of the pipe;

$D$ - pipe diameter $[\mathrm{m}]$

$\mathrm{D}_{3}$ - throat diameter $[\mathrm{m}]$

$\xi$ - loss coefficient [-];

$\varphi$ - coefficient of velocity [-];

$l$ - length of the respective part of the bypass

equipment (according to indexes);

$S$ - cross-sectional area of the respective part of the bypass equipment (according to indexes);

$l_{N o z}$ - nozzle length;

$l_{m c}$ - length of the mixing chamber;

$d_{m c}$ - diameter of the mixing chamber

$l_{3}$ - throat length;

$\eta_{\text {Dif }}$ - diffuser efficiency. 


\section{Conclusion}

The article describes the design of the reaction turbofan engine with the rear bypass of the air induced by the effects of the aerodynamic bypass duct. The design is based on the principle of gases flowing in the Bernoulli's tube, i.e. the aerodynamic paradox. The movement of the bypass air is a result of the effects of the pressure gradient between the flow of the bypass air and the flow of combustion gases. The article presents the principle and description of the bypass equipment as well as the results of measurements carried out with functional models. The testing of functional model and the measurements were carried out using the electric jet engine in the version of a single-flow engine and a turbofan engine. The results are presented in the enclosed tables and graphs, and from the technical point of view they are encouraging. The proposed design of the reaction engine facilitated achieving as much as a $50 \%$ increase in the thrust of the engine at the same input power, or approximately a $45 \%$ decrease in consumption while maintaining the same thrust of the engine. The equipment based on the proposed design may be used in civil and military aviation, in any suitable aircrafts and rockets which fly exclusively or partially in the Earth's atmosphere.

\section{Acknowledgement}

The proposed design represents the subject of the registered Utility Model No. 8725 in the Slovak Republic and the registered Utility Model No. 33657 in the Czech Republic.This work was supported by the project 055TUKE-4/2020 granted by the Ministry of Education, Science, Research and Sport of the Slovak Republic and by the Project of the Structural Funds of the EU, ITMS code: 26220220103.

\section{References}

[1]. Balara, M., Dupláková, D., \& Matisková, D. (2018). Application of a signal averaging device in robotics. Measurement, 115, 125-132.

[2]. Wong, B. B., \& Kokko, H. (2005). Is science as global as we think?. Trends in ecology \& evolution, 20(9), 475-476.

[3]. Haykin, S., \& Lippmann, R. (1994). Neural networks, a comprehensive foundation. International journal of neural systems, 5(4), 363-364.
[4]. Hennessy, J. L., \& Patterson, D. A. (2011). Computer architecture: a quantitative approach. Elsevier.

[5]. Balara, M.,Balara, A.(2020). Reaktívny dvojprúdový motor so zadnýmo tokom vzduchu. Úžitkový vzor č. 8725. ÚPV B. Bystrica, SK.

[6]. Khovanskyi, S., Pavlenko, I., Pitel, J., Mizakova, J., Ochowiak, M., \& Grechka, I. (2019). Solving the coupled aerodynamic and thermal problem for modeling the air distribution devices with perforated plates. Energies, 12(18), 3488.

[7]. Pavlenko, I., Liaposhchenko, O., Pitel, J., \& Sklabinskyi, V. (2019). Parameter identification of the Basset force acting on particles in fluid flow induced by the oscillating wall. Journal of Applied Mathematics and Computational Mechanics, 18(2), 53-63. DOI: 10.17512/jamcm. 2019.2.05.

[8]. Deng, Z., Boldea, I., \& Nasar, S. (1987). Forces and parameters of permanent magnet linear synchronous machines. IEEE transactions on magnetics, 23(1), 305-309.

[9]. Vittek, J., Vavrus, V., Malek, M., Buchner, P., \& Michalik, W. (2005, December). Prescribed closedloop speed dynamics control of the actuator employing linear permanent magnet synchronous motor. In 2005 IEEE International Conference on Industrial Technology (pp. 604-609). IEEE.

[10]. Panda, A., Olejárová, Š., Valíček, J., \& Harničárová, M. (2018). Monitoring of the condition of turning machine bearing housing through vibrations. The International Journal of Advanced Manufacturing Technology, 97(1-4), 401-411.

[11]. Smil, V.(1991). General energetics: energy in the biosphere and civilization. 1st edition New York: John Wiley \& Sons.

[12]. Cabeza, L. F. (2015). Advances in thermal energy storage systems: Methods and applications. In Advances in Thermal Energy Storage Systems (pp. 37-54). Woodhead publishing.

[13]. Andrejiova, M., Grincova, A., \& Marasova, D. (2016). Measurement and simulation of impact wear damage to industrial conveyor belts. Wear, 368, 400407.

[14]. Džunda, M., Kotianová, N., Dzurovčin, P., Szabo, S., Jenčová, E., Vajdová, I., ... \& Hanák, P. (2019). Selected Aspects of Using the Telemetry Method in Synthesis of RelNav System for Air Traffic Control. International Journal of Environmental Research and Public Health, 17(1).

[15]. Kelemen, M., Polishchuk, V., Gavurová, B., Szabo, S., Rozenberg, R., Gera, M., ... \& Blišt'an, P. (2019). Fuzzy model for quantitative assessment of environmental start-up projects in air transport. International journal of environmental research and public health, 16(19), 3585. 